\title{
Aging adults and rate of memory scan*
}

\author{
CHARLES W. ERIKSEN \\ University of Illinois, Champaign, Ill. 61820 \\ and \\ ROY M. HAMLIN and CONNIE DAYE \\ VA Hospital, Danville, Ill. 61832
}

Adults 20-25, 35-40, and 50-55 years old were examined on Sternberg's paradigm for rate of memory search. There were no differences between the two younger age groups in either overall performance or rate of memory scan, but the 50-55 year olds required approximately $50 \%$ more time per memory comparison than the two younger groups. Also, their intercepts were significantly greater.

The effects of advancing age in humans are easy to chronicle at the physiological level, but they are less readily characterized or pinpointed in terms of psychological functioning. Tests of intelligence or mental abilities are quite molar. They are subject to differences in motivation and past experience. In the past decade, however, experimental psychology has made considerable progress in conceptually distinguishing and operationally measuring substages and processes involved in the more global tasks of perceiving, remembering, and recognizing. An examination of aging effects on these more elemental processes would appear desirable.

Sternberg (1969), in a series of elegant experiments, has studied the rate of memory scan. The $S$ is given a set of single digits to remember, with sets consisting of from one to five different digits. After committing these digits to memory, $\mathrm{S}$ is presented with a test digit. His task is to decide as quickly as possible whether the test digit is a member of the set. This task leads to remarkably uniform results. Reaction time (RT) not only increases with the size of the memory set but also the function is essentially linear for positive trials, where the test stimulus is among the memory set, and for negative trials, where it is not. Sternberg has found among his Ss that RT increases approximately $38.40 \mathrm{msec}$ for each element in the memory set; he has interpreted his findings as indicating that, for this task, memory search is essentially serial in nature. That is, $\mathrm{S}$ compares the test stimulus successively with each member of the memory set, and each comparison operation requires approximately $38 \mathrm{msec}$. Since the slope of the function obtained for positive trials is essentially the same as for negative trials, it is further concluded that the search through memory is exhaustive. The essential nature of

*This investigation was supported by US Public Health Service Grant MH-1206 and US Public Health Service Research Career Program Award K6-MH-22014. these results has been confirmed in various laboratories.

It was our purpose in this experiment to explore the possibility of differences in rate of memory scan as a function of advanced chronological age in human adults.

\section{METHOD \\ Subjects}

All Ss were male patients at the Danville VA Hospital, who voluntarily participated in the experiment. There were six Ss in each of the three age groups: 20-25, 35-40, and 50-55 years. In addition to the age criteria, the Ss were selected on the basis of having a high degree of alertness, motivation, and freedom from drug medication.

\section{Apparatus and Stimuli}

Target stimuli were presented in a three-field Scientific Prototype tachistoscope, and the luminance of the stimulus fields was $3.5 \mathrm{~mL}$. Only the adaptation field containing a fixation cross and the first stimulus field were employed. The adaptation field terminated with onset of the stimulus field and returned with offset of the stimulus field. Target stimuli were presented for $1 \mathrm{sec}$. Reaction latency was measured by a Lafayette digital timer, activated simultaneously with the onset of the stimulus field of the t-scope and stopped by means of a Scientific Prototype voice key when S voiced either "yes" or "no." The stimuli were digits obtained from Para-tipe No. 11316 , placed in the center of a white vinyl card and positioned so as to occur $1 / 4 \mathrm{deg}$ of visual angle above the fixation point.

\section{Procedure}

The Ss were run individually. Following an extensive practice session, each completed three experimental sessions. Each experimental session began with a series of warm-up practice trials. The $S$ began the task by receiving a card containing one, two, or four digits. He was told to memorize the digits and then place the card on the table in front of him for ready reference. After several seconds had been allowed for $S$ to memorize the digits, he was told that within a second after E said "ready" a digit would appear in the tachistoscope and he was to respond "yes" or "no" as rapidly as possible, depending upon whether the presented digit was or was not one of the memorized set. He was told that on half of the trials the target digit would be a member of the memorized set.

An experimental session involved three blocks of 30 trials, one for each of the three sizes of the memory set. Half of the trials within a block were positive and half negative with respect to whether or not the digit was a member of the memorized set. The memory set was constant for all 30 trials in a block, but the particular set of memory digits was changed between sessions for each of the three set sizes. Order of blocks was counterbalanced between sessions and Ss. Trials on which an error occurred were repeated at the end of the block.

\section{RESULTS}

Mean RTs averaged by Ss over sessions were analyzed in a four-way analysis of variance (Ss, age groups, set size, and positive vs negative trials). The main effects due to age group, set size, and positive vs negative were all significant beyond the .01 level, as was the interaction between age group and set size.

In Fig. 1 mean RT is shown as a function of size of 


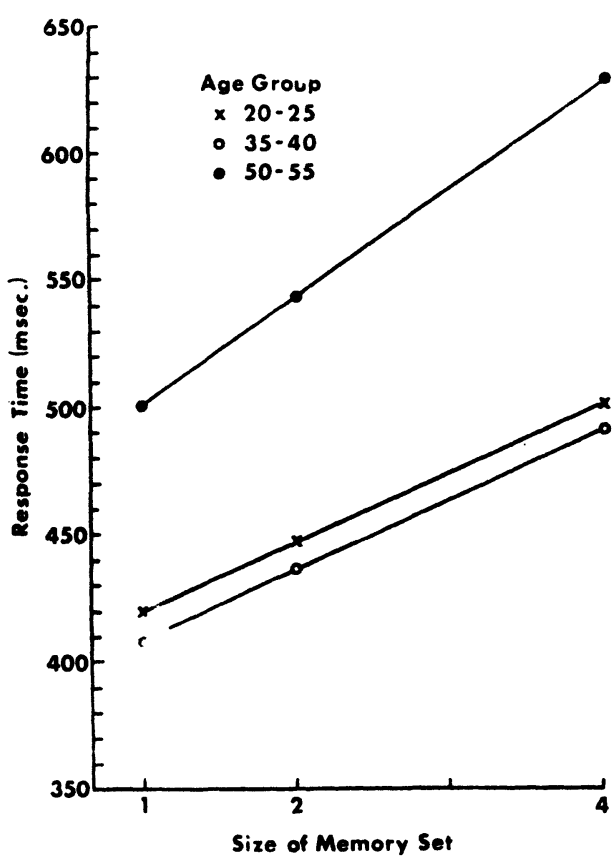

Fig. 1. Mean RT as a function of the size of the memory set for each of the three age groups.

Table 1

Percent Errors as a Function of $\mathrm{s}$ for Each Age Group

\begin{tabular}{cccc}
\hline & \multicolumn{3}{c}{ Size of } \\
\cline { 2 - 4 } Age & 1 & 2 & 4 \\
\hline $20-25$ & 2.8 & 6.3 & 8.0 \\
$35-40$ & 3.8 & 4.5 & 9.3 \\
$50-55$ & 3.0 & 2.5 & 7.16 \\
\hline
\end{tabular}

the memory set (s) for each of the three age groups. In this figure positive and negative trials have been averaged together. As is seen, there is little difference between the 20-25 age group and the 35-40 age group, either in terms of the overall RT or in the slope of the function relating RT to set size. The significant effect of age appears attributable to the longer RT for all set sizes by the 50-55 age group. Also, the significant Age Group by Set Size interaction is seen to consist of a steeper slope of the function relating set size to RT for this age group. The function relating $\mathrm{RT}$ to set size (s) is: $\overline{\mathrm{RT}}=$ $459+43 \mathrm{~s}$ for the oldest age group, $\overline{\mathrm{RT}}=383+28 \mathrm{~s}$ for the 35 - to 40 -year-old Ss, and $\overline{\mathrm{RT}}=394+27 \mathrm{~s}$ for the 25- to 30-year-old Ss.
Consistent with previous findings is the difference in overall RT between positive and negative trials. While the negative trials have longer latencies, the lack of a significant interaction term in the analysis of variance for positive and negative trials and set size suggests that they do not differ from positive trials in the slope of the function relating RT to set size. For the 50- to 55-year-old Ss, $\overline{\mathrm{RT}}=440+43 \mathrm{~s}$ and $\overline{\mathrm{RT}}=475+43 \mathrm{~s}$ for the positive and negative trials, respectively. For the other age groups, the respective functions are $\overline{\mathrm{RT}}=$ $362+24 \mathrm{~s}, \overline{\mathrm{RT}}=395+30 \mathrm{~s}$ for the 35 - to 40 -year-old Ss and $\overline{\mathrm{RT}}=374+27 \mathrm{~s}, \overline{\mathrm{RT}}=415+28 \mathrm{~s}$ for the 20 - to 25-year-old Ss.

Table 1 shows percent errors for each of the three age groups by size of memory set. As can be seen, the age groups are quite comparable and what differences do exist are nonsignificant. For all three groups there are more errors made with Set Size 4.

\section{DISCUSSION}

Results for all three age groups essentially replicate Sternberg's findings and are consistent with his interpretation that memory scan on this task is serial and exhaustive in character. The rate of scan is somewhat faster for our two younger groups than the rates reported by Sternberg. Differences in procedures between the Sternberg study and our experiment may account for the rate differences.

Of most interest is our finding that somewhere in the age range between 45 and 50 years, there appears to be a slowing in the rate of memory scan. Ss in the 50-55 age bracket are approximately $50 \%$ slower than the younger groups. If we interpret the underlying process as a serial comparison of the target stimulus with each item in the memory set, then the 50to 55-year-old Ss are requiring approximately $43 \mathrm{msec}$ per comparison, as opposed to $27 \mathrm{msec}$ for the two younger age groups.

The higher intercept RT value obtained for the older Ss is consistent with previous findings of slower RT among older Ss (Botwinick \& Brinley, 1962) and may be in part attributed to the motor components in the RT task. The present results showing a difference in scan rate, on the other hand, are indicative of a slowing in basic mental processes.

Due to the limitation inherent in a cross-sectional approach to aging problems, the present results can only be considered as suggestive with respect to aging on memory processing.

\section{REFERENCES}

Botwinick, J., \& Brinley, J. G. Aspects of reaction time set during brief intervals in relation to age and sex. Journal of Gerontology, 1962, 17, 295-301.

Sternberg, S. Memory scanning: Mental processes revealed by reaction time experiments. American Scientist, 1969, 57, 421-457.

(Received for publication January 29, 1973.) 